
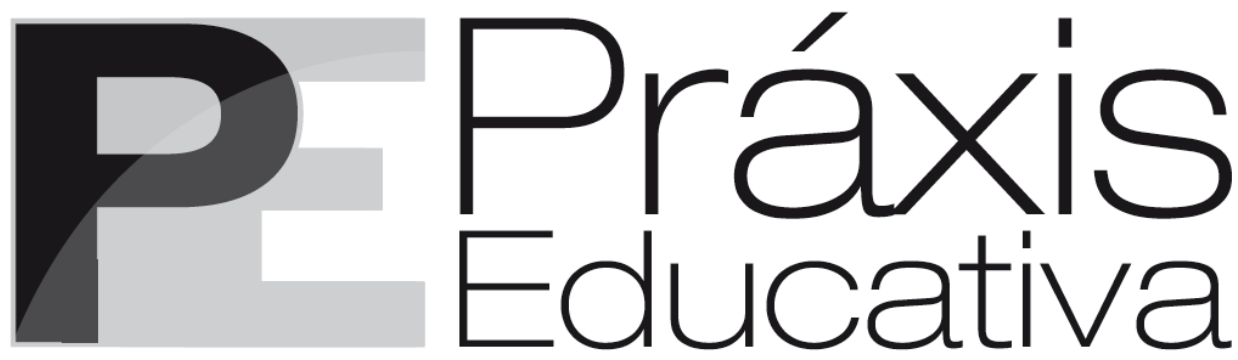

ISSN 1809-4031

eISSN 1809-4309

https://doi.org/10.5212/PraxEduc.v.16.15629.070

\title{
Pedagogia do oprimido, de Paulo Freire: suscitando diálogos e reflexões a
} partir de experiências em/com Educação

\section{Pedagogy of the oppressed, by Paulo Freire: eliciting dialogues and reflections from experiences in/with Education}

\section{Pedagogía del oprimido, de Paulo Freire: provocando diálogos y reflexiones a partir de experiencias en/con Educación}

\author{
Líbia da Silva Soares Busquet* \\ iD https://orcid.org/0000-0002-5544-0842 \\ Carlos César de Oliveira* \\ iD https://orcid.org/0000-0003-0961-1695 \\ Elaine Ferreira Rezende de Oliveira ${ }^{* * *}$ \\ iD https://orcid.org/0000-0002-5823-6708 \\ Jacqueline de Fatima dos Santos Morais (in memoriam) ${ }^{* * * *}$ \\ iD https://orcid.org/0000-0002-2100-265X
}

Resumo: Este artigo, construído a partir do encontro dos autores com a obra Pedagogia do oprimido, de Paulo Freire, configura três momentos: o vínculo da obra com o contexto da Educação Popular, com base em Streck e Esteban (2013), Streck (2009) e Carrillo (2013); a interface com o Teatro do oprimido, alicerçado em Boal (1991, 2009); e, por fim, a inspiração freiriana em práticas de alfabetização com crianças, conforme a Secretaria de Educação do Ceará (198-). Fundamentado em Bourdieu (2006), trata-se de um estudo que

* Doutoranda em Educação pelo Programa de Pós-Graduação em Educação Processos Formativos e Desigualdades Sociais da Faculdade de Formação de Professores da Universidade do Estado do Rio de Janeiro (FFP/UERJ). E-mail: <mcpessin@gmail.com>.

** Doutorando em Educação pelo Programa de Pós-Graduação em Educação da Pontifícia Universidade Católica do Rio de Janeiro (PPGE/PUC-Rio). E-mail: <carlosoliveira.prof@gmail.com>.

*** Professora do Departamento de Educação da Faculdade de Formação de Professores da Universidade do Estado do Rio de Janeiro (FFP/UERJ). E-mail: <oliveiraelaine1@gmail.com>.

**** Professora do Programa de Pós-Graduação em Educação Processos Formativos e Desigualdades Sociais da Faculdade de Formação de Professores da Universidade do Estado do Rio de Janeiro (FFP/UERJ). Jaqueline, presente, hoje e sempre! 
tem como referência as trajetórias sociais dos pesquisadores que, mediante diálogos e reflexões suscitados pela obra, expressam seus percursos pessoais, profissionais e suas práticas docentes. Constituído a partir de uma revisão de literatura, o estudo espera tecer alguns diálogos e contribuir com a produção e as pesquisas inspiradas na obra de Paulo Freire e na sua Pedagogia do oprimido, com vistas a fornecer uma fonte de atualização para os leitores.

Palavras-chave: Paulo Freire. Pedagogia do oprimido. Pensamento crítico.

Abstract: This article, constructed from the meeting of the authors with the work Pedagogy of the oppressed, by Paulo Freire, constitutes three moments: the link of the work with the context of Popular Education, based on Streck and Esteban (2013), Streck (2009) and Carrillo (2013); the interface with the Theatre of the oppressed, based on Boal $(1991,2009)$; and, finally, the Freirean inspiration in teaching children to read and write, according to the Department of Education of Ceará (198-). Based on Bourdieu (2006), this is a study that has as reference the social trajectories of the researchers who, through dialogues and reflections raised by the work, express their personal, professional and teaching practices. Constituted from a literature review, the text hopes to weave some dialogues and contribute to the production and research inspired by Paulo Freire's work and his Pedagogy of the oppressed, with a view to providing an update source for readers.

Keywords: Paulo Freire. Pedagogy of the oppressed. Critical thinking.

Resumen: Este artículo, construido a partir del encuentro de los autores con la obra Pedagogía del oprimido, de Paulo Freire, configura tres momentos: el vínculo de la obra con el contexto de la educación popular, con base en Streck y Esteban (2013), Streck (2009) y Carrillo (2013); la interfaz con el Teatro del oprimido, basado en Boal (1991, 2009); y, por último, la inspiración freiriana en prácticas de alfabetización con niños, según el Departamento de Educación de Ceará - Seduc-CE (198-). Fundamentado en Bourdieu (2006), se trata de un estudio que tiene como referencia las trayectorias sociales de los investigadores que, mediante diálogos y reflexiones planteadas por la obra, expresan sus itinerarios personales, profesionales y sus prácticas docentes. Constituido a partir de una revisión de literatura, el estudio espera tejer algunos diálogos y contribuir con producciones e investigaciones inspiradas en la obra de Paulo Freire y en su Pedagogía del oprimido, con vistas a proporcionar una fuente de actualización para los lectores.

Palabras clave: Paulo Freire. Pedagogía del oprimido. Pensamiento crítico.

\section{O início de um diálogo, de uma escrita coletiva}

Como um grande poema ou obra de dramaturgia, Pedagogia do oprimido não se esgota. Há sempre algo mais - outra perspectiva, outra visão, outra possibilidade do que Freire chamou de "um mundo mais amoroso".

Maxine Greene

Este artigo ${ }^{1}$ implica um desafio de dupla natureza: de um lado, a discussão acerca da obra Pedagogia do oprimido, de Paulo Freire; do outro, reflexões suscitadas por essa obra na trajetória (BOURDIEU, 2006) dos quatro autores deste texto. Partindo dessa premissa, procuramos dialogar com os sentidos que o referido livro tem nos provocado, tomando como base o lugar que cada um ocupa no campo da Educação, deixando-nos mergulhar naquilo que "[...] nos passa, o que nos acontece, o que nos toca" (LARROSA, 2002, p. 24); em outras palavras, na experiência que as ideias do Patrono da Educação Brasileira provocaram em nossas trajetórias de professores e professoras comprometidos/as com a Educação Popular.

\footnotetext{
${ }^{1}$ O estudo em questão foi realizado a partir de uma mesa redonda realizada em 17 de dezembro de 2018 pelo Programa de Pós-Graduação em Educação Processos Formativos e Desigualdades Sociais da Faculdade de Formação de Professores da Universidade do Estado do Rio de Janeiro (FFP/UERJ). A mesa contou com a presença dos quatro autores e teve como referência os 50 anos da obra Pedagogia do oprimido, lançada em 1968.
}

Práxis Educativa, Ponta Grossa, v. 16, e2115629, p. 1-19, 2021

Disponível em: <https://revistas2.uepg.br/index.php/praxiseducativa $>$ 
Um segundo desafio está relacionado à escrita deste texto, se considerarmos a ousadia de escrevê-lo a oito mãos. Ressaltamos que a sua produção ${ }^{2}$ representou negociações de tempos, de estilos e de sentidos do dizer, demonstrando um interesse comum nas discussões sobre as ideias de Paulo Freire e, em especial, sobre a Pedagogia do oprimido. Vale lembrarmos que se trata de um trabalho que emerge em um momento de perseguição às contribuições de Paulo Freire para a Educação brasileira. Momento de criminalização de suas ideias de igualdade e justiça social. Diante disso, compreendemos ser necessário retornar às obras desse autor, em especial à Pedagogia do oprimido, para problematizar a realidade, compreender a dimensão política do fazer pedagógico, como bem assinalou o próprio Freire (1987). Ao mesmo tempo, este estudo reafirma a potência do pensamento de Paulo Freire para o campo da Educação.

Dessa forma, compreendermos o impacto da atual conjuntura política sobre o campo educacional brasileiro pode nos auxiliar a perceber que "[...] em tempos de pós-verdades e Fake News, quando se fala em revisão da história, em fim das ideologias, em censura do trabalho docente, em neutralidade do fazer educativo [...] - urge retomar o pensamento pedagógico de Paulo Freire" (SANTOS; MELO; CAVALCANTE, 2021, p. 2), considerado um autor defensor de uma pedagogia libertadora, crítica e dialógica.

É importante lembrarmos que Paulo Freire escreveu Pedagogia do oprimido no Chile, durante os primeiros anos de seu exílio naquele país, concluindo-a em 1968 - período em que o Brasil enfrentou uma ditadura civil-militar, na qual o projeto das elites nacionais consistia em "[...] acomodar as classes populares emergentes, domesticá-las em algum esquema de poder ao gosto das classes dominantes" (WEFFORT, 1980, p. 17). No entanto, sua publicação só aconteceu em 1970, por meio de uma editora em Nova Iorque. Assinalamos, ainda, que passados mais de 50 anos de sua publicação, Pedagogia do oprimido passou a ser considerada uma das mais importantes do pensamento pedagógico universal. Uma das razões está em sua força política e epistemológica, bem como na sua atualidade (COSTA; SANTOS; VALE, 2020).

A obra Pedagogia do oprimido é um texto que não envelhece. Sobre ela, diversos estudos já foram realizados ${ }^{3}$, mas é sempre válido retomá-la em busca de elementos teóricos capazes de contribuir para (re)pensar a prática e as políticas educacionais. Destacamos que se trata de um livro publicado em 25 idiomas e que, no Brasil, já recebeu mais de 60 edições, sendo o único livro brasileiro a pertencer a lista dos 100 títulos mais referenciados pelas universidades de língua inglesa.

Quanto ao autor, ressaltamos que, além de escrever e publicar Pedagogia do oprimido, Paulo Freire escreveu muitas outras obras, ministrou inúmeras palestras em universidades nacionais e estrangeiras, demonstrando o seu compromisso ético e estético com a Educação. Após retornar ao Brasil, em 1980, Freire escreveu várias obras, dentre elas Pedagogia da Autonomia (1996), frequentemente lida em curso de formação de professores e de professoras. Também recebeu títulos internacionais, além de exercer a função de Secretário Municipal de Educação de São Paulo (1989-1991). Ao falecer, em 2 de maio de 1997, Freire já havia se consagrado como o mais importante educador brasileiro. Assim, reconhecendo a sua importância e a sua contribuição para o campo da Educação, voltamos o nosso olhar para Pedagogia do oprimido, tecendo diálogos com outras obras, com outros autores e autoras, para dar vida a este estudo.

\footnotetext{
2 Vale destacarmos que, para a produção deste artigo, utilizamos algumas ferramentas digitais. Inicialmente, trabalhamos com o Google Docs, de forma que todos pudessem acessar o texto e propor alterações. Usamos, ainda, o Whatsapp e o Google Meet para tecer os diálogos e (re)pensar o texto.

${ }^{3}$ No decorrer da revisão de literatura, chamamos a atenção para várias iniciativas - livros, eventos, dossiês temáticos - realizadas no ano de 2018, em comemoração ao $50^{\circ}$ aniversário de publicação da obra por nós estudada.
}

Práxis Educativa, Ponta Grossa, v. 16, e2115629, p. 1-19, 2021 Disponível em: <https://revistas2.uepg.br/index.php/praxiseducativa $>$ 
Em termos metodológicos, destacamos que Pedagogia do oprimido é, essencialmente, uma obra dialógica, democrática e participativa. Pensando nisso, buscamos, a partir do diálogo com autores e autoras - da revisão de literatura - e da reflexão sobre as nossas trajetórias, propor uma discussão prático-teórica. Com isso, a discussão por nós proposta amplia o diálogo com o próprio Freire $(1967,1978,1979,1992,1996)$ e nos leva a tecer novos diálogos com Costas, Santos e Vale (2020), Leite e Duarte (2007), Freire (2017), Greene (2017), Streck (2017), além de outros já anunciados e referenciados ao longo do texto.

Inspirados em Vosgerau e Romanowski (2014), partimos da premissa de que os estudos de revisão de literatura, como caminho metodológico, contribuem para examinar as contribuições das pesquisas nesse campo, para conhecer e analisar os estudos realizados, "[...] apontando a necessidade de melhoria do estatuto teórico metodológico, e mesmo as tendências de investigação". Para as autoras, tais estudos "[...] permitem a compreensão do movimento da área, sua configuração, propensões teóricas metodológicas, análise crítica indicando tendências, recorrências e lacunas" (VOSGERAU; ROMANOWWSKI, 2014, p. 167). Com base nessa ideia, acreditamos que a metodologia utilizada possibilitou uma imersão na obra estudada, ampliando, assim, a nossa compreensão sobre ela e uma reflexão sobre a nossa prática docente.

Ante o exposto, podemos dizer que este diálogo com Paulo Freire, a partir da Pedagogia do oprimido, nos possibilitou não somente revisar, ou melhor, revisitar o seu pensamento, mas também ampliar o nosso entendimento acerca dele. Assim, podemos dizer que este artigo é um pré-texto para reencontrarmos com Paulo Freire, sobretudo com a obra Pedagogia do oprimido, com base em três momentos: o vínculo com o contexto da Educação Popular; a interface com o Teatro do oprimido e a presença da "comunidade" em processos de alfabetização de crianças fundamentados no pensamento freiriano. Face a isso, somos instigados a (re)pensar a nossa prática educativa a partir das bases ontológicas, antropológicas, políticas e pedagógicas de seu pensamento crítico e libertador, de modo a reconhecer as suas incontáveis contribuições para a educação brasileira.

\section{O contexto da Educação Popular e da Pedagogia do oprimido: um olhar sobre o Brasil e a América Latina}

Analisar o contexto brasileiro, e em especial o surgimento da Educação Popular, tendo em vista o campo de recepção privilegiado das ideias freirianas, implica reconhecer os inúmeros retrocessos que o país tem vivido desde 2016. Essa conjuntura nacional revela as marcas do poder conservador enraizado estruturalmente em nosso país, sendo alimentado por projetos como "Escola sem Partido", que criminaliza as lutas por transformações educativas, em busca de conter os debates sobre possíveis melhorias nas condições de vida da população, a partir de ideais como igualdade e justiça social.

Em uma perspectiva histórica e social, para Carrillo (2013), a Educação Popular pode ser reconhecida como:

Corrente pedagógica e um movimento educativo, com profundas raízes na América Latina, que surge em torno das ideias de Paulo Freire e há várias décadas inspira reflexões e práticas de educadores de base, professores, animadores culturais, ativistas e militantes sociais, organizações e redes sociais [...]. Como pensamento pedagógico e prática educativa emancipadores, ela guarda estreita relação com outras correntes e movimentos afins, como a teologia da libertação e a igreja popular, a comunicação alternativa, a perspectiva de gênero, o feminismo popular e o movimento de mulheres, a pesquisa-ação participativa, o ambientalismo popular e o desenvolvimento alternativo. (CARRILLO, 2013, p. 18-19).

Práxis Educativa, Ponta Grossa, v. 16, e2115629, p. 1-19, 2021

Disponível em: <https://revistas2.uepg.br/index.php/praxiseducativa $>$ 
Ao analisar a Educação Popular, campo de atuação de Paulo Freire, abordagens macro e microssociais podem ajudar na compreensão da conjuntura brasileira e latino-americana. Nelas, políticas de retirada de direitos sociais avançam a passos largos sobre conquistas históricas das camadas populares. Neste trabalho, consideramos importante resgatar o percurso histórico da Educação Popular no cenário brasileiro, pois ele nos ajuda a ampliar a visão acerca dos impactos locais e nacionais das políticas públicas pensadas a partir de referenciais freireanos, em especial quando se trata de Educação de Jovens e Adultos (EJA).

Segundo Streck et al. (2014), há, na América Latina, uma proximidade entre a EJA e a Educação Popular, compreendida como:

Uma prática educativa e uma proposta pedagógica que se situa dentro e diante dos conflitos históricos das sociedades latino-americanas. Ela surge como uma manifestação que questiona a ordem de quem sabe e não sabe, quem ensina e aprende, de quem manda e quem obedece. Palavras como conscientização, libertação, empoderamento, humanização e emancipação procuram nomear os fins dessa educação. Estes dizem respeito ao destino da sociedade e ao tipo de mundo que pretendemos construir e por isso precisam estar na pauta de nossas discussões. (STRECK et al., 2014, p. 22).

No Brasil, o conjunto de ações que poderiam ser nomeadas de Educação Popular é extenso: Círculos de Cultura Popular, Ligas Camponesas, Movimento de Educação de Base, dentre muitos outros. Esses movimentos constituíram a história de uma prática educativa que faz da sociedade a sua sala de aula, recriando os papéis de educador e educadora e educando e educanda, com diferentes métodos e formas de intervenção no mundo.

Nas décadas de 1950 e 1960, a Educação Popular fundou um movimento pedagógico no cenário latino-americano por meio do qual a educação passou a ser vista como um instrumento de libertação para as classes subalternizadas (STRECK, 2009). Foram criados espaços de participação que representaram uma tomada de consciência. Um exemplo desse movimento ocorreu em Angicos, sob a liderança de Paulo Freire (WEFFORT, 1980). Segundo Streck (2009):

\begin{abstract}
Freire teve o mérito de captar e sistematizar como ninguém outro de seu tempo esse movimento e dar-lhe forma e consistência. Ele não inventou a pedagogia do oprimido mesclando Marx, Fromm, Sartre e outros pensadores, mas viu e ouviu o movimento pedagógico nas margens da sociedade e, então, para compreendê-lo, buscou os interlocutores. Ao mesmo tempo em que fez isso, Freire se pôs junto com o movimento, para o qual se tornou referência. (STRECK, 2009, p. 176).
\end{abstract}

Silva (2004), ao analisar o livro Pedagogia do oprimido, afirma que Freire concentra, na obra, esforços para descrever a dinâmica dos processos de dominação, muito mais do que demonstrar como a dominação se transfigura em um reflexo das relações econômicas. As críticas de Freire sobre educação tomam como base a estrutura e o funcionamento da educação institucionalizada. Dessa forma, o autor produziu uma importante e original crítica à escola tradicional. É central em sua epistemologia o conceito antropológico de cultura, entendendo cultura como criação e produção humana, sem distinção entre cultura erudita e cultura popular. Essa concepção ainda hoje influencia as ações de Educação Popular no Brasil e demais países da América Latina. Nessa perspectiva, o pensamento de Freire pode ser considerado pedagógico " [...] na medida em que ele não se limita a analisar como são a educação e a pedagogia existentes, mas apresenta uma teoria bastante elaborada de como elas devem ser" (SILVA, 2004, p. 58).

Sobre esse assunto, vale lembrarmos que um grupo de trabalho despontado em Pernambuco, no final dos anos de 1950, inovou ao relacionar a miséria, e não o analfabetismo, como o problema da educação das camadas populares do Nordeste brasileiro (FREITAS; BICCAS, 2009). Para esse grupo, a educação e a escola representavam não a reprodução da sociedade

Práxis Educativa, Ponta Grossa, v. 16, e2115629, p. 1-19, 2021

Disponível em: <https://revistas2.uepg.br/index.php/praxiseducativa $>$ 
existente, mas uma oportunidade para a ação e a transformação da sociedade, podendo dar respostas concretas às necessidades dos setores mais empobrecidos do país. De acordo com os autores:

\begin{abstract}
É importante ressaltar que nesse modelo a chamada "cultura específica" da comunidade teria um destaque muito especial, instaurando uma nova dinâmica, na qual a educação estaria intrinsecamente articulada àquilo que, naqueles anos, ganhou força e vitalidade: a ideia de cultura local. Assim, comunidade e escola, de maneira integrada, experimentariam concretamente um processo mútuo e simultâneo de transformação. Paulo Freire concebia o homem como um ser relacional e criador, aquilo que ele chamava de um agente da história, um ser "criador" e "consciente", portanto, capaz de exercer um papel ativo nos processos de transformações sociais. (FREITAS; BICCAS, 2009, p. 228).
\end{abstract}

Essa pedagogia crítica (STRECK, 2009) resultou no apontamento de Freire, no fim da década de 1960, como um importante nome no meio acadêmico. As suas ideias implicaram a afirmação de um novo paradigma que partia da realidade concreta dos educandos e das educandas. As práticas educativas e suas concepções de ensino e sociedade culminaram com o exílio de Freire por cerca de 15 anos. Depois disso, com a chamada "redemocratização do Brasil", ele retornou ao país, ainda em uma conjuntura de lutas por cidadania, direitos humanos e trabalhistas.

Muitas das propostas inspiradas em Freire foram incorporadas à Constituição de 1988, por meio da ação do Fórum da Participação Popular na Constituinte. Nessa perspectiva, mais do que nunca se notou a intervenção de movimentos sociais na construção de políticas públicas, em que se desenvolveu uma nova concepção acerca do Estado Brasileiro e da sociedade civil, dotada de forte capacidade propositiva com ações pautadas em organização autônoma e disputa nos espaços institucionais. "Paulo Freire havia insistido na ideia de que a ação pedagógica não é neutra, mas que ela é sempre ação política” (STRECK, 2009, p. 173).

No fim do século XX, o cenário apresentava variações múltiplas, em que as organizações de comunidades, bairros e ruas de localidades pobres traziam à tona reivindicações das camadas populares urbanas por direitos, melhores serviços públicos e educação de qualidade. Nas zonas periféricas das grandes cidades, "[...] o acesso a tais direitos já era realidade, mas tratava-se de uma realidade sujeita a impressionantes níveis de improvisação, deterioração e, por conseguinte, de desvalorização social" (FREITAS; BICCAS, 2009, p. 317).

A reconfiguração do capital levada a cabo na década de 1990 difundiu o discurso da globalização, em que uma educação voltada ao mercado invadiu os debates das políticas públicas educacionais brasileiras. Para Freire:

O discurso da Globalização que fala da ética esconde, porém, que a sua é a ética do mercado e não a ética universal do ser humano, pela qual devemos lutar bravamente se optamos, na verdade, por um mundo de gente. O discurso da globalização astutamente oculta ou nela busca penumbrar a reedição intensificada ao máximo, mesmo que modificada, da medonha malvadez com que o capitalismo aparece na história. O discurso ideológico da globalização procura disfarçar que ela vem robustecendo a riqueza de uns poucos e a miséria de milhões. (FREIRE, 1996, p. 144).

Nesse novo contexto, os movimentos sociais continuam a atuar pelas margens, se desenvolvendo em espaços ainda marginalizados e elaborando estratégias de ação que visam dar continuidade a luta por direitos sociais, civis e políticos.

No século XXI, surgem novos atores que atuam na Educação Popular, muitas vezes criticados por ligações contraditórias com o Estado e o capital financeiro. Uma dessas organizações são as organizações não-governamentais (ONGs), que se constituíram principalmente a partir da década de 1990 e passaram a atuar de forma privilegiada no cenário brasileiro, recebendo muitos

Práxis Educativa, Ponta Grossa, v. 16, e2115629, p. 1-19, 2021

Disponível em: < https:// revistas2.uepg.br/index.php/praxiseducativa $>$ 
investimentos públicos e privados (GOHN, 2013; NEVES, 2002). Esses novos atores produzem alternativas para a construção de uma pedagogia inspirada em práticas da Educação Popular freiriana, atuando e modificando a vida concreta das camadas populares do Brasil. Essas ações buscam impactar a educação e a vida dos grupos sociais subalternizados, pois, para Paulo Freire:

\begin{abstract}
Impedidos de atuar, de refletir, os homens encontram-se profundamente feridos em si mesmos, como seres de compromisso. Compromisso com o mundo, que deve ser humanizado para a humanização dos homens, responsabilidade com estes, com a história. Este compromisso com a humanização do homem, que implica uma responsabilidade histórica, não pode realizar-se através do palavrório, nem de nenhuma outra forma de fuga do mundo, da realidade concreta, onde se encontra os homens concretos. (FREIRE, 1979, p. 18-19).
\end{abstract}

Nesse sentido, podemos afirmar que as práticas de Educação Popular da contemporaneidade continuam sendo produzidas e reproduzidas nas periferias urbanas, associações da sociedade civil, ONGs, Quilombos, assentamentos de sem-terra e demais movimentos sociais, guardando características que foram inspiradas na vida e na obra de Paulo Freire. Essas práticas podem ser consideradas libertadoras, na medida em que:

A Pedagogia do oprimido que, no fundo, é a pedagogia dos homens empenhando-se na luta por sua libertação, tem suas raízes aí. E tem que ter nos próprios oprimidos, que se saibam ou comecem criticamente a saber-se oprimidos, um dos seus sujeitos. Nenhuma pedagogia realmente libertadora pode ficar distante dos oprimidos [...]. Esta é a razão pela qual, como já afirmamos, esta pedagogia não pode ser elaborada nem praticada pelos opressores. Seria uma contradição se os opressores, não só defendessem, mas praticassem uma educação libertadora. (FREIRE, 1987, p. 22).

Contudo, tais práticas devem ser analisadas sem perder de vista os interesses postos pela inserção desses movimentos com inspiração freiriana no cenário internacional, pois, a partir do final do século XX, o Estado brasileiro responsabilizou a sociedade civil pelo atendimento das necessidades sociais, de lazer e cultura dos mais pobres, para os quais os equipamentos públicos não chegam. Desse modo, é importante que as ações inspiradas na Educação Popular possam ser acompanhadas de perto, pois corremos o risco de que operem

[...] para esgotar os esforços reivindicatórios e as lutas sociais, uma vez que estão atendendo a uma demanda projetada para agentes externos. Além disso, é também uma forma de regular as ações das inúmeras organizações sociais criadas no país com o objetivo de atender as populações empobrecidas, mudando o lugar social das organizações: de instituidoras de processos educativos passaram a meras executoras de processos já instituídos no bojo dos ideais com as quais tais políticas foram concebidas. (STRECK et al., 2014, p. 107-108).

Contudo, para analisar o nosso Sistema de Ensino, bem como a escolarização das camadas populares no Brasil e na América Latina, é preciso levarmos em conta que há, nas nossas escolas públicas, um caráter historicamente excludente, oriundo da própria sociedade capitalista (ESTEBAN; TAVARES, 2013).

O contexto social e político mais amplo que trouxemos nesta parte do texto nos ajuda a compreender as implicações pedagógicas geradas pela obra Pedagogia do oprimido. Não é um livro inocente, esvaziado de intensões ou proposições. Freire (1987, p. 12) dedicou essa obra "[...] aos esfarrapados do mundo e aos que com eles lutam", conforme afirmado nas primeiras linhas do seu livro, demonstrando o seu mais profundo desejo por uma ação libertadora, pois, para ele, é a educação que produzirá a libertação.

Apontada como a principal obra de Freire, Pedagogia do oprimido assinala - em um convite à reflexão - que, entre oprimidos e oprimidas e opressores e opressoras, há uma relação de

Práxis Educativa, Ponta Grossa, v. 16, e2115629, p. 1-19, 2021

Disponível em: < https:// revistas2.uepg.br/index.php/praxiseducativa $>$ 
Pedagogia do oprimido, de Paulo Freire: suscitando diálogos e reflexões a partir de experiências...

desumanização e, consequentemente, de alienação, não apenas dos oprimidos e das oprimidas, mas também dos opressores e das opressoras. Nesse sentido, a educação exerceria uma função libertadora.

Fundamentados pelo seu pensamento e conscientes de que a ação e a reflexão (práxis) resultam em um movimento dialético, que possibilita (re)pensarmos as nossas práticas educativas, traremos, a seguir, algumas provocações suscitadas pela obra de Paulo Freire em nossas trajetórias sociais. Com isso, buscamos compartilhar a força das ideias de quem nunca abandonou a Educação Popular, problematizando as aproximações entre a obra em estudo: a Pedagogia do oprimido, de Paulo Freire, e o Teatro do oprimido, de Augusto Boal.

\section{Uma conversa entre o Teatro do oprimido e a Pedagogia do oprimido}

Entre os diálogos tecidos acerca da obra Pedagogia do oprimido, uma das autoras deste artigo destacou que, em 1992, foi realizado um curso teatral organizado pela Secretaria Municipal de Educação e Cultura de São Gonçalo, Rio de Janeiro, pautado na proposta do Teatro do oprimido, de Augusto Boal. É importante sinalizarmos que o curso ofertado na cidade de São Gonçalo teve à frente de sua direção o ator, coreógrafo e monitor Marcus Vargens, formado pelo dramaturgo Augusto Boal e, portanto, com bastante experiência em técnicas e exercícios acerca do Teatro do oprimido.

Durante o curso, os participantes tiveram a oportunidade de estudar com o próprio Augusto Boal, na Casa de Cultura Pascoal Carlos Magno, em Santa Tereza, na cidade do Rio de Janeiro. Nessa ocasião, os participantes puderam compreender alguns pontos convergentes e singulares entre a proposta da Pedagogia do oprimido, de Paulo Freire, e o Teatro do oprimido, ressaltando-se que os dois autores defendem, em suas obras, uma transformação social por meio da educação e da cultura local. A partir dessa perspectiva, é oportuno destacarmos alguns pontos em que suas concepções se aproximam em seus campos de atuação.

Segundo Boal (2009), o Teatro do oprimido pode ser considerado uma tentativa de se ensaiar a realidade, de modo que arte e estética provoquem ações que ultrapassem os limites do palco e atinjam a vida real para transformá-la. O método desenvolvido por Boal foi difundido, a exemplo da pedagogia de Freire, em diversos países e foi batizado como Teatro do oprimido em homenagem a Paulo Freire.

Por compreender o teatro como potente ferramenta na busca por transformação social, com e pelos oprimidos e pelas oprimidas, Boal criou e difundiu seu método de teatro baseado em jogos. Nele, os atores e as atrizes têm a liberdade para criar e se expressar diante de situações diversas de opressão. Boal escreveu seus primeiros textos sobre o Teatro do oprimido nos anos de 1960 e 1970, sendo reunidos no livro Teatro do oprimido e outras poéticas políticas, publicado nos anos de 1980. Sobre o autor, afirma-se que foi uma das lideranças do Teatro de Arena em São Paulo, nos anos de 1960, se tornando, posteriormente, uma referência do teatro brasileiro, como diretor, teórico e autor teatral.

O Teatro do oprimido (BOAL, 1991), é uma metodologia que alia ação social com teatro. É constituído de uma série de ações e fazeres teatrais improvisados, visando transformar as relações de poder na sociedade capitalista, por intermédio da busca de uma conscientização política do público e dos atores envolvidos no processo do fazer teatral em cena. Trata-se, portanto, de uma metodologia em que a atuação, a discussão e a transformação dos atores e das atrizes e do público se dão pela ação em cena. Apresenta uma possibilidade de fazer teatral na qual a divisão dos papéis dos/as atores/atrizes-espectadores/as, quem atua e assiste têm papéis relevantes. Podemos dizer,

Práxis Educativa, Ponta Grossa, v. 16, e2115629, p. 1-19, 2021

Disponível em: <https://revistas2.uepg.br/index.php/praxiseducativa $>$ 
então, que o Teatro do oprimido, de Boal (1991), estimula a que todos sejam participantes ativos da ação representada nas cenas, cujo espectador se transforma em "espect-ator".

A partir dessa perspectiva, os "espect-atores", tanto atores e atrizes como plateia, mostram nas cenas, com gestos e falas, o que está ocorrendo na realidade. Eles exercitam, trazendo para a cena, ações do cotidiano, de suas vidas, em uma perspectiva consciente, cujo objetivo consiste em fortalecê-los/as para uma atuação que resulte na transformação de suas próprias vidas e na sociedade. Logo, observamos que o Teatro do oprimido possui marcas da Pedagogia do oprimido, tendo em vista ser construída com e pelo oprimido ao invés de para ele, como bem sinalizou Freire (1987). Essa prática coloca-se como um caminho na busca pela humanização dos homens e das mulheres. Nesse sentido, tanto Freire como Boal defendem que é necessário que a pedagogia "[...] faça da opressão e de suas causas objeto da reflexão dos oprimidos, de que resultará o seu engajamento necessário na luta por sua libertação" (FREIRE, 1987, p. 17). Entretanto, não se pode deixar de exercitar a consciência, como nos faz ver Freire (1987) ao longo de sua obra, de que é importante a valorização do conhecimento formal curricular, pois, na Pedagogia do oprimido, o que importa é a forma como trabalhamos esse currículo a partir da realidade dos sujeitos e de sua problematização.

Atentando para a relação entre Boal e Freire, podemos inferir que, em sua base, o Teatro do oprimido possui uma importante função pedagógica, pois estimula a capacidade reflexiva do oprimido e da oprimida, advertindo-o/a de que ele/a também, em seus comportamentos e atitudes, pode colocar-se no papel do opressor ou da opressora. Por esse motivo, sua busca consiste em partir da realidade dos espectadores e das espectadoras e dos atores e das atrizes, suscitando reflexões que possibilitem transformar sua realidade. Nessa perspectiva, o diferencial do Teatro do oprimido, bem como a sua relação com a Pedagogia do oprimido, está no fato de que as pessoas que estão na condição de espectador/a (receptor/a) podem se tornar sujeitos em cena e trazer para ela sua própria realidade, a fim de criticá-la e modificá-la, possibilitando algum nível de transformação. Além disso, o fazer teatral pode suscitar uma reflexão acerca da atuação, levando-os a observar se o comportamento adotado durante o espetáculo foi um comportamento que figura a manutenção das relações de opressão ou a serviço da libertação.

Conforme afirmado por Boal (1991), o Teatro do oprimido não é composto apenas por uma técnica, mas por diversas técnicas, tendo em vista que um dos objetivos é colocar os atores e as atrizes diante de problemas políticos e sociais, dando apoio aos oprimidos e às oprimidas nas lutas que travam contra a opressão. Assim, por meio de diversas técnicas como Teatro-jornal, Teatro-fórum, Teatro-invisível, estimula-se que os/as envolvidos/as levem para seu cotidiano a discussão que foi realizada nas cenas, com fins a ajudar na transformação de sua condição de oprimido e de oprimida. Essa busca pela transformação ocorreu em diversas áreas, inclusive no teatro e nas rádios, pois:

A partir das décadas de 1960-1970, eclodiram, na América Latina, movimentos alternativos de comunicação social que se caracterizaram fundamentalmente pela apropriação dos meios de comunicação de massa por populações e sujeitos marginalizados que, na luta diária para afirmar ou garantir sua existência, reinventam formas de luta e de expressão. Esses movimentos expandiram-se enormemente na década de 1990. Com a premissa de "dar voz aos que não têm voz", os movimentos adotaram e, em muitos casos ainda adotam, como principais bandeiras de luta, a democratização da comunicação e a superação da noção mecânica de comunicação fundamentada na transmissão de informações de emissores e fontes ativas a receptores passivos. (COCCO; CAIMI, 2021, p. 2).

Com base nessa perspectiva, o Teatro do oprimido foi bastante vivenciado em espaços como sindicatos e associações de moradores/as nas décadas de 1970, seguindo os acontecimentos

Práxis Educativa, Ponta Grossa, v. 16, e2115629, p. 1-19, 2021

Disponível em: <https://revistas2.uepg.br/index.php/praxiseducativa $>$ 
Pedagogia do oprimido, de Paulo Freire: suscitando diálogos e reflexões a partir de experiências...

àquela época, onde se podia fazer demonstração de caminhos em que o Teatro-fórum, e outras formas do Teatro do oprimido, colaborassem para se compreender expressões de manifestações culturais (ZOTESSO, 2010).

No que se refere à Pedagogia do oprimido, é importante lembrarmos que ela estimula a prática da escuta, da conversa, da afetividade. Em sua obra, Freire (1987) fala sobre os modos de opressão da educação capitalista, que tem como base a disciplinarização dos corpos. Partindo dessa acepção, Freire discute duas posições frente aos processos de ensino: a concepção bancária, cujo enfoque está na transmissão de conhecimentos; e a concepção libertadora, que se pauta no diálogo e na capacidade de, criticamente, problematizar a realidade. Assinalamos, ainda, que, na educação bancária, o educando e a educanda são vistos como um "fundo bancário" no qual o educador e a educadora depositam informações que vão sendo arquivadas. Com um comportamento dócil, passivo, ou meramente receptor, o educando e a educanda necessitam, grande parte das vezes, de modo mecânico, memorizar aquilo que ouvem na escola.

Já na educação libertadora, segundo Freire (1987), educador e educadora e educando e educanda atuam juntos/as, em busca de descobrir e redescobrir o que há no mundo. $\mathrm{O}$ conhecimento que ocorre nesse processo é crítico, uma vez que é construído de modo reflexivo, em uma tentativa constante de desvendar a realidade, assumindo uma posição mais crítica diante dela. O saber construído dessa forma implica a problematização da realidade e o desejo de transformar o mundo. Todavia, para que ocorra a educação problematizadora, é fundamental o diálogo entre educandos e educandas e educadores e educadoras, com uma participação efetiva por meio da qual se possa opinar sobre quais conteúdos serão trabalhados, de forma que não fiquem desvinculados da realidade que vivem, de acordo com o que defende Freire (1987).

Por fim, consideramos oportuno destacar que as obras de Freire (1987) e Boal (1991) convergem, sobretudo, no que se refere ao "diálogo", que, segundo Freire (1987, p. 45), trata-se de um "[...] encontro dos homens, mediatizados pelo mundo, para pronunciá-lo, não se esgotando, portanto, na relação eu-tu". A partir dos dois autores, entendemos que, nessa relação dialógica, se articulam a proposta pedagógica com os interesses dos indivíduos que se encontram oprimidos e os princípios fundantes da luta contra a opressão.

Alinhado com o pensamento freiriano, Augusto Boal (2009) considera que o processo de conscientização da realidade acontece com base na relação ação-reflexão-ação, na acepção de práxis defendida por Freire. Diante disso, podemos perceber que, para Boal, assim como para Freire, é fundamental que, além de se compreender a realidade, os sujeitos busquem nela intervir para transformá-la; assim sendo, tanto a educação quanto o teatro assumem o seu caráter político. No Teatro do oprimido, para que isso ocorra, o processo envolve, inclusive, a "desmecanização" do corpo, possibilitando uma tomada de consciência individual e coletiva.

Com base nos dois autores, somos convidados a refletir sobre o atual contexto, marcado por intolerância, silenciamento, injustiças, fake news, entre outras questões que afetam a educação. Isso nos leva a defender uma proposta pedagógica que privilegie o diálogo em seus fazeres diários, em uma constante ação-reflexão sobre a prática, a fim de buscar novas práticas baseadas no princípio da alteridade e nas potentes relações entre educadores e educadoras e educandos e educandas.

Pensando nessa relação dialógica entre educadores e educadoras e educandos e educandas em uma ação pedagógica que se dá por meio das "práxis" (FREIRE, 1987), a discussão que se segue resulta de uma experiência em alfabetização, fazendo-nos pensar nos atravessamentos da obra Pedagogia do oprimido em nossas vidas de educadores e de educadoras. Desta vez, trazemos as reverberações implicadas por uma prática educativa fundamentada no pensamento freiriano,

Práxis Educativa, Ponta Grossa, v. 16, e2115629, p. 1-19, 2021 Disponível em: <https://revistas2.uepg.br/index.php/praxiseducativa $>$ 
levando em consideração o tempo e o espaço da escola e dos processos formativos que se dão fora dela, como possibilidades para o enriquecimento da formação do professor e da professora.

\title{
Um diálogo sobre "comunidade" a partir da alfabetização com crianças
}

Bastante recorrente na obra freiriana, a categoria "comunidade" traz-nos alguns elementos para pensar no seu papel formativo e na sua capacidade de contribuir para a organização das pessoas em defesa de um bem comum. Ela reflete essa unidade, democraticamente organizada, capaz de pensar, definir e discutir pautas acerca do cotidiano. Como sugere Freire (1987), pensar uma educação a partir da comunidade implica pensar um processo educativo enraizado na realidade local. A partir desse olhar para o local, da sua compreensão, é possível ampliar a visão acerca de outros contextos: regional, nacional, global.

Tomamos como referência para esta discussão, a trajetória de um dos autores, cuja alfabetização - na infância - foi pautada no pensamento freiriano. Nesse sentido, o presente estudo, além da sua função prático-teórica, busca aprofundar a discussão acerca da comunidade e do seu papel em práticas educativas, ao voltar-se para experiências de alfabetização com crianças fundamentadas no pensamento de Paulo Freire, a exemplo dos estudos de Leite e Duarte (2007) e Oliveira (2020, 2021).

É importante destacarmos que os estudos relacionados ao pensamento freiriano especialmente no campo da alfabetização - são mais recorrentes na educação de pessoas jovens e adultas. Conforme sugerem Peloso e Paula (2021):

\begin{abstract}
No Brasil, predominam os estudos voltados à educação de pessoas jovens e adultas, às análises dos processos de opressão, à humanização e às desigualdades sociais. Entretanto, nas últimas décadas, a obra freiriana tem sido estudada por pesquisadoras e pesquisadores que reconhecem também as influências do pensamento de Paulo Freire para a educação de diferentes crianças e infâncias. (PELOSO; PAULA, 2021, p. 2).
\end{abstract}

Ao revisar a literatura, o estudo realizado por Peloso e Paula (2021) aponta alguns investimentos de pesquisadores entre Paulo Freire e a educação das infâncias. Com elas, concordamos que os currículos escolares "[...] desconsideram as realidades e os saberes populares das crianças discriminando-as, principalmente as das classes populares" (PELOSO; PAULA, 2021, p. 6). Diante disso, voltamos a atenção para o trabalho de alfabetização com infâncias que teve como base as "palavras geradoras" (FREIRE, 1979). Sobre esse assunto, partimos dos estudos de Leite e Duarte (2007) e Oliveira (2020, 2021), nos quais encontramos referências a práticas de alfabetização desenvolvidas com palavras (entre 15 e 20) que servem como base para os processos de alfabetização, entre elas a categoria "comunidade", conforme a Secretaria de Educação do Ceará - Seduc-CE (CEARÁ, 198-). Segundo a Cartilha da Ana e do Zé:

Comunidade é povo unido. O povo se ajuda. O povo unido se ama. O povo unido é forte. A união faz a comunidade. O Zé diz: Viva a comunidade. A Ana ajuda a comunidade. A comunidade ajuda a vida? Como a comunidade ajuda o povo? O povo é unido? Como a gente faz a união? Menino ajuda a comunidade? A escola é comunidade? Povo unido é bom?4 (CEARÁ, 198-, p. 95)5.

Diante disso, dedicamos especial atenção a dois eixos temáticos: o primeiro diz respeito ao trabalho com as palavras geradoras em processos de alfabetização das infâncias; e o segundo,

\footnotetext{
${ }^{4}$ Sobre esse assunto, ver a página 6 de Oliveira (2019).

${ }^{5}$ Não faremos referência ao ano, visto que a cartilha não traz data de sua publicação, mas os registros sugerem que foi publicada entre 1982 e 1985.
}

Práxis Educativa, Ponta Grossa, v. 16, e2115629, p. 1-19, 2021

Disponível em: < https://revistas2.uepg.br/index.php/praxiseducativa $>$ 
tomando como base uma das 18 palavras geradoras trabalhadas pela Seduc-CE (CEARÁ, 198-) na alfabetização de crianças, está pautado na problematização da categoria "comunidade", a qual foi discutida por Paulo Freire em Pedagogia do oprimido.

A respeito da alfabetização, iniciamos este diálogo afirmando que: "Alfabetizar, para Freire, é valorizar a sabedoria resultante das experiências culturais locais do alfabetizando, possibilitando que ele avance para além de suas crenças em torno de si e do mundo" (LEITE; DUARTE, 2007, p. 42). Diante disso, acreditamos que o trabalho com as palavras geradoras, em virtude da participação coletiva e do diálogo, reflete o cotidiano da comunidade, pois valoriza o local e as experiências que dele resultam. Além disso, o trabalho com as palavras geradoras resulta em uma prática educativa por meio da qual os educandos e as educandas são estimulados/as a conhecer e explorar (novas) palavras, a partir de suas referências de mundo, resultantes de experiência socioculturais (FREIRE, 1979). Assim, à medida que conhecem a escrita das palavras, eles/as escrevem e descrevem o seu mundo, a sua comunidade, as suas referências locais.

Sobre as palavras geradoras, Freire (1979, p. 43) destaca que, uma vez selecionadas, se criam "[...] situações (pintadas ou fotografadas) nas quais são colocadas as palavras geradoras em ordem crescente de dificuldades fonéticas". Assim, de forma gradativa, educandos e educandas vão ampliando o seu conhecimento sobre a língua e sobre o mundo, a partir de elementos da sua vivência. $\mathrm{O}$ autor alerta-nos, ainda, que as palavras geradoras precisam exprimir o contexto cultural dos educandos e das educandas, por isso são retiradas da vida, e nunca escolhidas unilateralmente pelo docente. Afinal, como afirma Freire (1979, p. 42) tais palavras "[...] são constituídas por vocábulos carregados de certa emoção", são "[...] palavras típicas do povo... ligadas à sua experiência vivencial”.

Nesse sentido, como parte da comunidade local, a escola surge como um espaço para oportunizar novas leituras - a partir do encontro com as palavras, com a sua escrita - alimentando a premissa do "Ser mais" (FREIRE, 1987), do "ser alguém no mundo" (OLIVEIRA, 2021), por meio de uma educação que rompe com a marginalização do "não saber ler e escrever", que busca romper e superar formas de exclusão (escolar e social), possibilitando a realização de novas leituras de mundo, de intervir na realidade para transformá-la. Nesse contexto, a escola é compreendida como um espaço capaz de contribuir para que o "ser" - educando e educanda - se torne capaz de construir a sua "autonomia" (FREIRE, 1996) e fazer as próprias escolhas, reconhecendo na educação uma possibilidade de mudança, visto que cultiva valores muito significativos, como a coletividade, a solidariedade, o respeito aos saberes da comunidade e a valorização da cultura local, conforme ressalta Oliveira (2019, p. 3).

Com base nisso, defendemos que a escola deve ter clareza da importância desse "lugar social”' (STRECK, 2017, p. 117), pois é nele que educandos e educandas estão inseridos/as. Logo, a compreensão da escola como parte desse espaço - desse lugar social - torna-se fundamental para que as ações pedagógicas nela desenvolvidas reflita e problematize a realidade de seus/suas estudantes. Diante disso, ressaltamos a urgência de uma Pedagogia do oprimido capaz de levar em consideração a realidade das comunidades rurais e das periferias urbanas, pois são lugares em que o acesso à escola ainda é bastante limitado. A respeito disso, Oliveira (2021) sugere a ideia de uma educação represada, tendo em vista condições geográficas (zona rural), sociopolíticas que incidem sobre a educação das crianças oriundas das classes populares.

Para Leite e Duarte (2007, p. 44): “As crianças, em qualquer idade, gostam de ser ouvidas, de falar sobre os acontecimentos mais recentes e seus problemas existenciais". Por esse motivo,

\footnotetext{
${ }^{6}$ Ao tratar de "lugar social" Streck (2017, p. 117) destaca que a "Pedagogia do oprimido escancara o fato da não neutralidade pedagógica e assume claramente o lugar social onde essa pedagogia é feita”.
}

Práxis Educativa, Ponta Grossa, v. 16, e2115629, p. 1-19, 2021 
acreditamos que o trabalho com as palavras geradoras, conforme sugerem os autores, valoriza a leitura, a escuta, a participação dos educandos e das educandas. Além disso, destacamos o papel da cultura local no processo de alfabetização, como destaca (OLIVEIRA, 2020), referindo-se à leitura de cordel, às brincadeiras e à história da comunidade. A cultura local é rica em expressões e linguagens, mas estas são muitas vezes negligenciadas, esquecidas, pelas políticas, pelo currículo e, por conseguinte, pelas práticas escolares.

Sobre o trabalho com as palavras geradoras, Leite e Duarte (2007) destacam o envolvimento das crianças no processo de sua escolha, o papel dos diálogos, da escuta sensível às crianças, da participação. Por meio dessa prática, é possível explorar a história de vida dos/as estudantes, contribuindo para que eles/as olhem para a sua realidade e reflitam sobre ela. Com relação ao professor ou à professora, afirmam que cabe a ele/a " [...] explorar a pluralidade cultural e respeitar a pluralidade das vozes, os diversos saberes e opiniões, porém, sem deixar de as orientar e refletir criticamente" (LEITE; DUARTE, 2007, p. 44).

Um dos fatores relevantes deste trabalho diz respeito à participação ativa de professores e de professoras em todas as etapas, desde a escolha das palavras geradoras até o trabalho em sala de aula. Oliveira (2020), ao discutir esse assunto, destaca o importante papel da participação docente na elaboração da $A$ Cartilha da Ana e do Zé (CEARÁ, 198-), conforme já destacamos no decorrer desta seção. Em outras palavras, podemos dizer que professores e professoras participam ativamente da elaboração do currículo. E este, por sua vez, parte da realidade local, valorizando o cotidiano da escola e da comunidade na qual ela está inserida.

Portanto, os dois estudos, tanto o de Oliveira (2020) quanto o de Leite e Duarte (2007), nos remetem ao que estes últimos chamaram de "adaptação do método de Paulo Freire na alfabetização de crianças” (LEITE; DUARTE, 2007, p. 22). Para nós, problematizá-los em diálogo com a Pedagogia do oprimido, vem acentuar a importância da construção coletiva, participativa, democrática, envolvendo educandos e educandas, educadores e educadoras e comunidade na escolha de palavras geradoras de mundo. No caso da experiência relatada por Oliveira (2020), para além de sua significação, chamamos atenção para o fato de "Ana" e "Zé" (CEARÁ, 198-) referirse às letras " $A$ " e " $Z$ ", início e fim do alfabeto, mas também criar uma unidade semântica com o local, visto que são nomes comuns no interior do Ceará. Além disso, atentamos para o fato de que a Cartilha é "da/do" e não "para" a Ana e o Zé.

Atentos a essa construção, retomamos uma discussão freiriana de que a "pedagogia do oprimido" é uma pedagogia "do/com o oprimido" e não uma pedagogia para o oprimido e a oprimida. É, assim, uma pedagogia que envolve o fazer coletivo, a reflexão crítica e, por que não dizer, a participação da/na comunidade. Advertimos que o emprego do vocábulo "para", no contexto da educação, implica uma educação prescrita por setores privilegiados da sociedade, entre eles grupos editoriais, que, ao produzir "para" a educação, deixam de lado, por exemplo, as peculiaridades locais e os aspectos culturais que atravessam a vida dos/das estudantes. Por esse motivo, a Pedagogia do oprimido:

Nasce também inspirada em sua sabedoria de entender e enfrentar os problemas da
realidade; de seu poder de desvelar com singularidade as coisas óbvias do cotidiano; de
sua valorização ao senso comum como ponto de partida para o conhecimento político-
científico-filosófico, e de sua fé, respeito e crença nos seres humanos. (FREIRE, 2017,
p. 29).

Partindo desse pressuposto, de que processos de alfabetização freiriano são pensados a partir da realidade dos educandos e das educandas, retomamos a discussão acerca da comunidade, compreendendo a escola como uma comunidade inserida em um contexto mais amplo, que Freire (1987, 1992) chama de "comunidade local". O autor defende uma escola centrada na relação

Práxis Educativa, Ponta Grossa, v. 16, e2115629, p. 1-19, 2021

Disponível em: < https://revistas2.uepg.br/index.php/praxiseducativa $>$ 
Pedagogia do oprimido, de Paulo Freire: suscitando diálogos e reflexões a partir de experiências...

educador/a-educando/a e na comunidade local. Uma escola na qual o aprendizado resulte de diálogos, leituras e olhares - ora inquietantes, ora inquietados - para o contexto local.

Após explanarmos sobre o primeiro eixo temático, a partir dele iniciamos a discussão acerca da categoria "comunidade". Acentuamos que, além de ela figurar como uma palavra geradora, é comum identificá-la no pensamento freiriano, inclusive em Pedagogia do oprimido. Diante disso, faremos uma breve discussão sobre o conceito de comunidade em Freire, ao mesmo tempo em que destacamos como a comunidade pode contribuir com a educação e com a superação de formas de opressão.

Tomando a comunidade como referência, lançamos mão de uma busca em algumas obras de Paulo Freire, a fim de identificarmos a sua incidência e a forma como o autor a compreende. Tendo em vista que se trata de uma vasta obra, selecionamos algumas obras por bloco, inspirados em Scocuglia (2020), que sugere uma divisão da obra de Paulo Freire em três blocos: o da educação como prática da liberdade, o dos escritos africanos e os dos livros dialógicos. Partindo desse pressuposto, identificamos que a comunidade aparece com mais intensidade em Educação como Prática da Liberdade (8), Pedagogia do oprimido (15); Cartas à Guiné-Bissau: registros de uma experiência em processo (31); Pedagogia da Esperança: um retorno com a pedagogia do oprimido (13) ${ }^{7}$. Isso significa dizer que se trata de um conceito presente em diferentes momentos do pensamento freiriano.

A partir dessas obras, podemos considerar a comunidade como associação, união de pessoas em torno de um mesmo propósito ou objetivos, o que pode ser notado nas referências a "comunidades locais", "comunidades agrárias", "comunidades indígenas", "comunidades de base”, "comunidade camponesa". Foi possível percebermos que, em vários momentos, Freire aponta a organização em comunidade como sinal de enfrentamento, de luta, de resistência ao opressor e à opressora. É interessante observarmos que esse enfrentamento se dá também no campo da Educação, por meio do diálogo, da participação e da troca de saberes, contrariando a prática de ensino transmissionalista adotada pela "educação bancária" (FREIRE, 1987), anunciada na seção anterior. Assim sendo, a comunidade é apresentada como um contributo para novas formas de ação, tendo em vista a capacidade das pessoas se organizarem e, coletivamente; problematizar a realidade local e enfrentar as formas de exclusão, tomando frente ante os problemas que as afligem.

De tais problemas, destacamos as questões referentes à educação, daí a importância da participação da comunidade, do diálogo entre a família e a escola. Participar é assumir a sua responsabilidade social. Logo, é um ato político. A participação atuante em diferentes espaços, como no bairro, na Igreja, em sindicatos, em associações de moradores/as ou em organismos da escola contribui não somente para pensar a escola, mas para formar os sujeitos que ao participarem desenvolvem um aprendizado a partir do olhar problematizador para a comunidade. É nesse sentido que entendemos o processo de escolha das palavras geradoras (FREIRE, 1979) como uma etapa participativa e, portanto, formativa, visto que envolve diversos sujeitos e experiências.

Como organização popular, a comunidade assume um importante papel ao participar da escola, contribuindo com o desenvolvimento de projetos, de atividades, participando das tomadas de decisões, entre outros. Vale lembrarmos que estas são ações que resultam em outros espaços formativos e, consequentemente, na formação das pessoas. A respeito disso, Nakashima, Almeida e Cardoso (2020, p. 8) afirmam que "[...] os espaços educacionais escolares e não escolares podem

\footnotetext{
${ }^{7}$ A busca foi realizada em livros digitais (Formato em PDF), por meio do Menu Editar $>>$ Localizar $>>$ Abrir pesquisa total do Reader $>>$ No documento atual $>>$ (inserção de: comunidade) Pesquisar. Os resultados apresentados referem-se àqueles encontrados nessa busca.
}

Práxis Educativa, Ponta Grossa, v. 16, e2115629, p. 1-19, 2021 Disponível em: <https://revistas2.uepg.br/index.php/praxiseducativa $>$ 
contribuir para quebrar a dualidade opressor e oprimido, ao criar oportunidades de investigação crítica da realidade social"'.

Pensando com Freire (1978), concluímos que a integração entre escola e comunidade, além de integrar esforços na defesa de uma educação pública popular, estimula a "[...] solidariedade social, o trabalho baseado na ajuda mútua, a criatividade, a unidade entre o trabalho manual e o trabalho intelectual, a expressividade, os educandos irão criando novas formas de comportamento de acordo com a responsabilidade que devem ter diante da comunidade" (FREIRE, 1978, p. 40). Desse modo, a comunidade funciona como espaço onde há troca de saberes, mobilização e organização popular (FREIRE, 1992), seja nas lutas por educação, seja nas lutas políticas travadas em busca de melhorias para o local.

Diante disso, observamos que tanto em Pedagogia do oprimido como em Pedagogia da esperanç, ao retornar à pedagogia do oprimido, a "comunidade local" é apresentada por Paulo Freire como um lugar onde há aprendizagem e troca de saberes - um lugar no qual a Educação Popular acontece. Nessa acepção, as experiências relatadas por Leite e Duarte (2007) e por Oliveira (2020), por meio de uma articulação prático-teórica, destacam a realização de experiências democráticas, de práticas educativas e de conteúdos que fazem sentido para educandos e educandas, visto que refletem a sua comunidade local. Mediante isso, acreditamos ser fundamental que a escola, apesar dos muros, abra-se à comunidade, a fim de compreender o território no qual está inserida. A escola é parte da comunidade, logo não pode alhear-se a ela.

Após discutirmos os eixos temáticos - alfabetização com crianças e comunidade -, concluímos que, em uma sociedade marcada por situações de opressão, a presença de ações reflexivas, coletivas, rompe com uma educação individualista, dogmática, mecanicista, e abre caminhos para uma educação libertadora, solidária, humanizadora e, portanto, comunitária. A partir disso, acreditamos que a discussão proposta reitera o entendimento de que a educação das classes populares passa pela relação entre escola e comunidade. Afinal, por meio dessa relação, torna-se possível conhecer e, quiçá, compreender a leitura de mundo que educandos e educandas trazem para a escola. Assim, ao caminhar de mãos dadas, a comunidade e a escola - a comunidade-escola - podem contribuir com o desenvolvimento de práticas educativas que valorizem a cultura local e o fortalecimento da luta por políticas públicas, entre elas, as políticas em defesa da escola pública, comunitária e popular.

\section{E assim findamos este diálogo...}

Acreditamos que este artigo - fruto de diálogos - representou um movimento de reencontrar em nós traços, imagens e recordações da presença do livro Pedagogia do oprimido em nossas trajetórias de vida e de trabalho no campo da Educação. Tal obra é marcada pela afirmação de uma proposta de educação crítica e libertadora, contribuindo para que possamos pensar na dimensão política da educação. Afinal, apesar de ter sido escrita em outro momento histórico, de ditadura e exílio, ela nos traz elementos para pensarmos a educação atual, sobretudo no que se refere ao fato de que professores e professoras assumam uma postura neutra diante das injustiças, das desigualdades sociais, dos cortes na educação e da perseguição à categoria docente.

Nesse sentido, a realização desta discussão - por meio de um “quefazer" (FREIRE, 1996) coletivo e dos múltiplos olhares sobre conceitos e práticas experienciadas por sujeitos aprendentes

\footnotetext{
${ }^{8}$ Vale lembrarmos que, para além da relação escola e comunidade, assim como na educação, a comunidade reflete um caráter político, tendo em vista a sua proximidade com o "engajamento", a "militância", o "ativismo", a "mobilização" e a "participação", conceitos também recorrentes no pensamento de Paulo Freire.
}

Práxis Educativa, Ponta Grossa, v. 16, e2115629, p. 1-19, 2021 Disponível em: <https://revistas2.uepg.br/index.php/praxiseducativa $>$ 
Pedagogia do oprimido, de Paulo Freire: suscitando diálogos e reflexões a partir de experiências...

e inacabados - resultou no encontro com Paulo Freire, suas concepções, seus princípios, seus conteúdos e seus métodos. Uma discussão que, política e epistemologicamente, implicou olhar para as nossas trajetórias sociais e refletir sobre as nossas ações pedagógicas, no intuito de trazer contribuições para que outros sujeitos - sobretudo professores e professoras - possam, a partir do pensamento freiriano, problematizar e (re)inventar os caminhos da sua prática educativa.

Quando voltamos o nosso olhar para o Teatro do oprimido e para a Pedagogia do oprimido, lembramos que a nossa ênfase foi discutirmos e defendermos uma Educação Popular, voltada aos educandos, às educandas, aos sujeitos pobres, aos/às analfabetos/as, aos/às despossuídos/as de terra e de políticas públicas adequadas, como sujeitos de cultura, do conhecimento e da história. Instigados tanto por Freire quanto por Boal, este estudo é um convite a (re)pensar a relação educativa com respeito, amorosidade e, sobretudo, com um compromisso ético.

Por meio das reflexões e dos questionamentos levantados, cremos ter cumprido com o nosso propósito, ao debatermos sobre as contribuições do pensamento freireano na nossa formação, compreendendo que "[...] somente um ser que é e está sendo no tempo que é seu, um ser histórico, somente este é capaz, por tudo isto, de comprometer-se" (FREIRE, 1979, p. 8). Um compromisso evidenciado ao destacarmos o diálogo, a relação entre escola e comunidade, a práxis e a cultura popular como elementos imprescindíveis à construção de um conhecimento crítico, que favoreça as práticas educativas problematizadoras, com fins à emancipação dos sujeitos.

Lembramos, ainda, que Pedagogia do oprimido foi o ponto de partida para esta discussão. Cada sujeito, porém, pode lançar outro olhar e problematizá-lo de acordo com sua trajetória, compreendida por Bourdieu (2006) como percurso de vida, que ocorre por meio da relação entre as condições materiais e simbólicas das vidas dos indivíduos - por meio da interação entre a interiorização da exterioridade e da exteriorização da interioridade.

Assim sendo, afirmamos que a obra adotada como referência para este estudo se constitui como um testemunho atemporal. Um texto que não deixa de nos dizer novidades e que, também, não permite um silenciamento do leitor ou da leitora. Em Paulo Freire, especialmente em Pedagogia do oprimido, ganha centralidade os educandos, as educandas, suas experiências, suas linguagens, seu contexto social em diálogo com experiências, linguagens e contexto social, os educadores, as educadoras, constituindo uma relação prático-teórica que valoriza os múltiplos saberes.

Considerando todas as questões e as reflexões aqui expostas, procuramos não nos determos a uma mera exposição dos fundamentos da obra freiriana. Isso seria contradizer o seu pensamento. Algo talvez mais fácil, porém menos original. Nesse sentido, buscamos reacender o diálogo - ainda tão caro à educação - tomando como base a boniteza das ideias de Freire, e reencontrarmo-nos com um pensamento que continua vivo, vigoroso e que inspira a todos nós, professores e professoras e estudantes, a lermos o mundo com criticidade e com a esperança (FREIRE, 1992), por uma educação "das" e "com" as classes populares.

Paulo Freire, presente!

\section{Referências}

BOAL, A. Teatro do oprimido e outras poéticas políticas. Rio de Janeiro: Civilização Brasileira, 1991.

BOAL, A. A estética do oprimido. Rio de Janeiro: Garamond, 2009.

Práxis Educativa, Ponta Grossa, v. 16, e2115629, p. 1-19, 2021

Disponível em: < https://revistas2.uepg.br/index.php/praxiseducativa $>$ 
BOURDIEU, P. A ilusão biográfica. In: FIGUEIREDO, J.; FERREIRA, M. (org.). Usos e abusos da história oral. 8. ed. Rio de janeiro: FGV, 2006. p. 183-191.

CARRILLO, A. T. A Educação Popular como prática política e pedagógica emancipadora. In: STRECK, D.; ESTEBAN, M. T. (org.). Educação popular: lugar de construção social coletiva. Petrópolis: Vozes, 2013. p. 15-32.

CEARÁ. Secretaria de Educação. A Cartilha da Ana e do Zé. Fortaleza: Seduc, [198-].

COCCO, R.; CAIMI, F. H. Um movimento pedagógico e o pedagógico em movimento: as vertentes Freireanas da comunicação e da radiodifusão comunitária. Práxis Educativa, Ponta Grossa, v. 16, e2116319, p. 1-23, 2021. DOI: https://doi.org/10.5212/praxeduc.v.16.16319.007

COSTA, A. M. M.; SANTOS, S. C. M. dos; VALE, E. C. do. 50 anos da Pedagogia do oprimido: quem são os oprimidos de hoje? Olhar de professor, Ponta Grossa, v. 23, p. 1-15, e2020.16699.209209229146.0820, 2020. DOI: https://doi.org/10.5212/olharprofr.v.23.16699.

ESTEBAN, M. T.; TAVARES, M. T. G. Educação Popular e a Escola Pública: Antigas questões e novos horizontes. In: STRECK, D.; ESTEBAN, M. T. (org.). Educação Popular - Lugar de construção social coletiva. Petrópolis: Vozes, 2013. p. 293-307.

FREIRE, A. M. A. A Pedagogia do oprimido, como parte da "pedagogia do oprimido" de Paulo Freire. In: FREIRE, A. M. A. (org.). Pedagogia da Libertação em Paulo Freire. 2. ed. São Paulo: Paz \& Terra, 2017. p. 27-36.

FREIRE, P. Educação como prática da liberdade. Rio de Janeiro: Paz \& Terra, 1967.

FREIRE, P. Cartas à Guiné-Bissau: registros de uma experiência em Processo. 2. ed. Rio de Janeiro: Paz \& Terra, 1978.

FREIRE, P. Educação e mudança. 12. ed. São Paulo: Paz \& Terra, 1979.

FREIRE, P. Pedagogia do oprimido. 17. ed. Rio de Janeiro: Paz \& Terra, 1987.

FREIRE, P. Pedagogia da esperança: um reencontro com a Pedagogia do Oprimido. Rio de Janeiro: Paz \& Terra, 1992.

FREIRE, P. Pedagogia da autonomia: saberes necessários à prática educativa. 25. ed. São Paulo: Paz \& Terra, 1996.

FREITAS, M. C.; BICCAS, M. S. História Social da Educação no Brasil. São Paulo: Cortez, 2009.

GREENE, M. Reflexões sobre a pedagogia do oprimido de Paulo Freire. In: FREIRE, A. M. A. (org.). Pedagogia da Libertação em Paulo Freire. 2. ed. São Paulo: Paz \& Terra, 2017. p. 75-78.

GOHN, M. G. Sociedade Civil no Brasil: movimentos sociais e ONGs. Meta: Avaliação, Rio de Janeiro, v. 5, n. 14, p. 238-253, maio/ago. 2013.

LARROSA, J. Notas sobre a experiência e o saber de experiência. Revista Brasileira de Educação, Rio de Janeiro, n. 19, p. 20-28, jan./abr. 2002. DOI: https://doi.org/10.1590/s1413$\underline{24782002000100003}$

LEITE, O. S. L.; DUARTE, J. B. Aprender a ler o mundo. Adaptação do método de Paulo Freire na alfabetização de crianças. Revista Lusófona de Educação, Lisboa, v. 10, n. 10, p. 22-37, 2007. 
NAKASHIMA, R. H. R.; ALMEIDA, R. C. M. de; CARDOSO, B. S. Pensamento Educacional Freireano: perspectivas humanistas e libertadoras. Olhar de Professor, Ponta Grossa, v. 23, p. 112, e-2020.16764.209209229432.0828, $2020 . \quad$ DOI: https://doi.org/10.5212/olharprofr.v.23.16764

NEVES, L. M. W. O neoliberalismo e a redefinição das relações Estado-Sociedade. In: NEVES, L. M. W. (org.). O empresariamento da educação. Novos contornos do Ensino Superior no Brasil dos anos 1990. São Paulo: Xamã, 2002. p. 105-114.

OLIVEIRA, C. C. de. Ana, Zé e eu: o "nós" e os "nós" da educação a partir de experiências em escola no campo. In: REUNIÃO NACIONAL DA ANPED, 39., 2019, Niterói. Anais eletrônicos [...]. Niterói: ANPEd, 2019. Disponível em: http://39.reuniao.anped.org.br/wpcontent/uploads/sites/3/trabalhos/5618-TEXTO_PROPOSTA_COMPLETO.pdf. Acesso em: 30 jul. 2021.

OLIVEIRA, C. C. de. Pastoral da Juventude do Meio Popular "cirandando" em formação: aproximações entre a pedagogia pastoral e a pedagogia libertadora. 2020. 251 f. Dissertação (Mestrado em Educação) - Universidade do Estado do Rio de Janeiro, Faculdade de Formação de Professores, Rio de Janeiro, 2020.

OLIVEIRA, C. C. de. Do lado de cá do rio, desafios das infâncias ante uma escolarização represada. In: ALENCAR, C.; PESSANHA, F.; TAVARES, M. T. G. (org.). Ao mestre com carinho: professoras e professores das infâncias em diálogo com Paulo Freire. Rio de Janeiro: Nau Editora, 2021. No prelo.

PELOSO, F. C.; PAULA, E. M. A. T. de. A constituição do ser humano a partir de diversos contextos e experiências nas infâncias: a complexidade das obras de Paulo Freire. Práxis Educativa, Ponta Grossa, v. 16, e2116609, p. 1-18, 2021. DOI: https://doi.org/10.5212/praxeduc.v.16.16609.018

SANTOS, L. A.; MELO, V.; CAVALCANTE, M. S. A. O. Paulo Freire e a resistência à naturalização da ordem social vigente. Práxis Educativa, Ponta Grossa, v. 16, e2016433, p. 1-15, 2021. DOI: https://doi.org/10.5212/praxeduc.v.16.16433.008

SCOCUGLIA, A. C. "Medo e Ousadia". Videoaula 4/4 da "Jornada Paulo Freire Sim", realizada pelo Instituto Paulo Freire (IPF), 2020. Disponível em: https:// cursos.unifreireonline.org/jornada-paulo-freire-sim-38d4f067-50ea-4604-b220-

f1a02b16e6b2. Acesso em: 30 jul. 2021.

SILVA, T. T. Documentos de identidade: uma introdução as teorias do currículo. Belo Horizonte: Autêntica, 2004.

STRECK, D. R. Uma pedagogia do movimento: os movimentos sociais na obra de Paulo Freire. Revista de Educação Pública, Cuiabá, v. 18, n. 36, p. 165-177, jan./abr. 2009.

STRECK, D. R. Uma pedagogia do (outro) descobrimento. In: FREIRE, A. M. A. (org.). Pedagogia da Libertação em Paulo Freire. 2. ed. São Paulo: Paz \& Terra, 2017. p. 113-122.

STRECK, D. et al. Educação popular e docência. São Paulo: Cortez, 2014.

STRECK, D.; ESTEBAN, M. T. (org.). Educação Popular - Lugar de construção social coletiva. Petrópolis: Vozes, 2013. 
VOSGERAU, D. S. R.; ROMANOWSKI, J. P. Estudos de revisão: implicações conceituais e metodológicas. Revista Diálogo Educacional, Curitiba, v. 14, n. 41, p. 165-189, jan./abr. 2014. DOI: https://doi.org/10.7213/dialogo.educ.14.041.ds08

WEFFORT, F. Educação e Política (Reflexões sociológicas sobre uma pedagogia da Liberdade). In: FREIRE, P. (org.). Educação como prática da liberdade. 11. ed. Rio de Janeiro: Paz \& Terra, 1980. p. 3-26.

ZOTESSO, A. Teatro do oprimido: incorporações mediáticas de uma poética popular. 2010. 104 f. Dissertação (Mestrado em Comunicação e Semiótica) - Pontifícia Universidade Católica de São Paulo, São Paulo, 2010.

Recebido em 10/08/2020

Versão corrigida recebida em 11/01/2021

Aceito em 29/07/2021

Publicado online em 04/08/2021 